\title{
Endophthalmitis Caused by Agrobacterium radiobacter following Intravitreal Aflibercept for Diabetic Retinopathy
}

\author{
Landon J. Rohowetz ${ }^{a} \quad$ Nicolas A. Yannuzzi $^{b}$ Sunil Gupta ${ }^{c}$ \\ Nimesh A. Patel ${ }^{b} \quad$ Darlene Miller $^{\mathrm{b}}$ Harry W. Flynn Jr. ${ }^{\mathrm{b}}$ \\ aUniversity of Missouri - Kansas City School of Medicine, Kansas City, MO, USA; \\ ${ }^{b}$ Department of Ophthalmology, Bascom Palmer Eye Institute, Miami, FL, USA; \\ 'Retina Specialty Institute, Pensacola, FL, USA
}

\section{Keywords}

Agrobacterium radiobacter · Endophthalmitis · Aflibercept

\begin{abstract}
Agrobacterium (Rhizobium) radiobacter is a gram-negative bacillus rarely implicated in ocular disease. A 79-year-old male who performed extensive yardwork following intravitreal injection with aflibercept for diabetic macular edema developed endophthalmitis caused by Agrobacterium radiobacter on post-injection day 7 . The patient was treated with vitreous tap and intravitreal injection of vancomycin and ceftazidime with clearance of the infection and restoration of his baseline visual acuity at 20/80.

(C) 2020 S. Karger AG, Basel
\end{abstract}

\section{Introduction}

Intravitreal anti-vascular endothelial growth factor (VEGF) therapy is the mainstay of treatment for many retinal diseases [1]. Although rare, endophthalmitis is a feared complication of anti-VEGF treatment, with an incidence ranging from $0.013 \%$ to $0.061 \%$ [2-4]. The most frequently identified pathogens causing endophthalmitis after intravitreal anti-VEGF treatment are coagulase-negative staphylococci, Streptococcus viridans, and Staphylococcus 
aureus [2, 5], with significant vision loss often associated with streptococcus infection [2]. The most significant risk factor for endophthalmitis is violation of aseptic technique during injection [6-9]. Other potential risk factors include anterior chamber paracentesis and eyelid manipulation prior to injection $[10,11]$.

Agrobacterium (Rhizobium) radiobacter is an aerobic gram-negative bacillus predominantly found in soil [12]. Systemic infection due to Agrobacterium radiobacter is rare and most commonly occurs in immunocompromised patients [13-17]. While Agrobacterium radiobacter endophthalmitis has been reported, most cases have occurred after cataract surgery [1822]. Agrobacterium radiobacter endophthalmitis after aflibercept injection following a potential post-treatment soil exposure is described.

\section{Case Report/Case Presentation}

A 79-year-old male with past medical history of insulin-dependent type II diabetes mellitus and past ocular history of moderate nonproliferative diabetic retinopathy with clinically significant macular edema presented to the retina clinic complaining of decreased vision and pain in the right eye. The patient was undergoing regular treatment with intravitreal aflibercept and received his most recent injection 7 days prior to presentation. All injections were performed in the office after povidone iodine prep. He was not immunosuppressed but admitted to trimming extensive foliage throughout his property the same day after receiving his most recent injection.

On exam, visual acuity was hand motion in the right eye, decreased from a baseline of $20 / 80$. He was noted to have corneal stromal haze, mutton-fat keratic precipitates, $3+$ anterior chamber cell, and a 0.5 -mm hypopyon with fibrin in the pupillary margin. Posterior chamber intraocular lens was in place. Funduscopic exam revealed vitreous debris and posterior cells. B-scan demonstrated hyperechogenicity of the vitreous and vitreous echoes without signs of retinal detachment (Fig. 1). Optical coherence tomography (OCT) demonstrated diminished signal transmission (Fig. 2a, b).

Vitreous samples were collected via needle aspiration and intravitreal vancomycin and ceftazidime were administered. The vitreous culture demonstrated Agrobacterium (Rhizobium) radiobacter and the patient was started on oral azithromycin and levofloxacin. At the 1month follow-up, visual acuity had returned to baseline of 20/80 and the infection had resolved (Fig. 2c).

\section{Discussion/Conclusion}

Agrobacteria are gram-negative bacilli known to cause tumors in plants [19]. The first case of human infection with Agrobacterium radiobacter was described in 1980 in a patient with endocarditis [23] and the first case of endophthalmitis due to Agrobacterium radiobacter was reported in 1996 following cataract surgery [19], with few reports since then [18, 20-22, 24].

Predominantly found in soil, the development of Agrobacterium radiobacter endophthalmitis has been associated with outdoor activities after cataract surgery [19, 21]. To our knowledge, exposure to soil following intravitreal injection has not been described as a purported cause of endophthalmitis. This is a possibility in our case given the patient's performance of yardwork following injection and the known association between soil exposure and 
Agrobacterium radiobacter endophthalmitis after cataract surgery [19, 21]. Indeed, patients who have undergone either intraocular surgery or intravitreal injection should be encouraged to avoid outdoor activity involving potential exposure to soil immediately following the procedure [21].

While most systemic infections due to Agrobacterium radiobacter tend to occur in immunocompromised patients [13-17], all reported cases of Agrobacterium radiobacter endophthalmitis have occurred in the absence of immune suppression [18-22, 24]. This tendency to cause endophthalmitis in the absence of immunosuppression, particularly after intraocular lens implantation, has been attributed to Agrobacterium radiobacter's propensity to adhere to silicone substances such as intraocular lens implants [21,25]. Small quantities of silicone oil droplets are indeed present in intravitreal anti-VEGF injections [26]. However, their presence is unlikely to predispose to infection, as silicone oil has demonstrated antimicrobial activity and may in fact be beneficial in cases of endophthalmitis associated with retinal detachment requiring vitrectomy $[27,28]$.

The clinical presentation of Agrobacterium radiobacter endophthalmitis is similar to endophthalmitis caused by other microorganisms, with common findings including decreased vision, pain, hypopyon, and vitreous opacities. Diagnosis is ultimately confirmed by isolation of the pathogen via vitreous or aqueous humor sampling. While isolation of Agrobacterium radiobacter is possible after 2 to 3 days of incubation on blood-enriched media or MacConkey agar, difficulties in phenotypic identification may delay results or even cause incorrect identification [20,21]. As such, a faster and more accurate method involving RNA sequencing may be utilized in cases requiring rapid diagnosis, although culture remains necessary for susceptibility testing $[20,29]$.

While Agrobacterium radiobacter is an organism of low virulence [19, 22], it possesses a variety of mechanisms for antimicrobial resistance, possibly as a result of its coexistence with antibiotic-producing organisms in soil [21,30,31]. Susceptibility patterns include frequent resistance to tobramycin and occasional resistance to other common antimicrobial agents such as trimethoprim-sulfamethoxazole, ampicillin, gentamicin, amikacin, ceftazidime, and vancomycin $[12,15,21]$. This tendency for resistance against antimicrobial agents approved for intravitreal injection may underscore the importance of oral antibiotic therapy as an adjunct to intravitreal treatment of Agrobacterium radiobacter endophthalmitis [21]. Some have suggested an empiric antibiotic regimen of intravitreal aminoglycosides such as amikacin in conjunction with oral carbapenems and fluoroquinolones in the treatment of endophthalmitis after cataract surgery [20,21]. Indeed, cases of Agrobacterium radiobacter endophthalmitis refractory to classic empiric antimicrobial therapy have been reported after cataract surgery, ultimately requiring pars plana vitrectomy and, in one case, removal of intraocular lens implant $[20,21]$. As such, careful consideration of the most appropriate antibiotic regimens in conjunction with antimicrobial susceptibility patterns is essential in preserving visual potential in patients with Agrobacterium radiobacter endophthalmitis [18, 20, 22, 24]. As demonstrated previously in neovascular age-related macular degeneration, our patient's OCT findings prior to anti-VEGF injection improved after treatment of his endophthalmitis [32].

In summary, Agrobacterium radiobacter is a soil-dwelling organism that rarely causes disease in humans. Soil exposure has been associated with endophthalmitis following cataract surgery but not intravitreal injection. A patient with Agrobacterium radiobacter endophthalmitis following intravitreal aflibercept injection is described. As such, we introduce soil exposure as a potential source of endophthalmitis following intravitreal injection and present the first known case of Agrobacterium radiobacter endophthalmitis after aflibercept injection. 


\section{Statement of Ethics}

The authors have no ethical conflicts to disclose. Written informed consent was obtained from the patient. The manuscript conforms to the tenets of the Declaration of Helsinki and does not include any information which may reveal the patient's identity.

\section{Disclosure Statement}

The authors have no conflicts of interest to declare.

\section{Funding Sources}

The Department of Ophthalmology receives grant support from the NIH Center Core Grant P30EY014801 (Bethesda, Maryland) and the Research to Prevent Blindness Unrestricted Grant to UM.

\section{Author Contributions}

Landon J. Rohowetz: data analysis and interpretation, manuscript drafting, and literature search. Nicolas A. Yannuzzi and Nimesh A. Patel: manuscript drafting and revision. Sunil Gupta and Darlene Miller: patient assessment, data collection, and manuscript revisions. Harry W. Flynn Jr.: manuscript conception, design, revision, and final approval.

\section{References}

1 Yeung AW, Abdel-Daim MM, Abushouk AI, Kadonosono K. A literature analysis on anti-vascular endothelial growth factor therapy (anti-VEGF) using a bibliometric approach. Naunyn Schmiedebergs Arch Pharmacol. 2019 Apr;392(4):393-403.

2 Yannuzzi NA, Gregori NZ, Rosenfeld PJ, Relhan N, Patel NA, Si N, et al. Endophthalmitis associated with intravitreal injections of anti-VEGF agents at a tertiary referral center: in-house and referred cases. Ophthalmic Surg Lasers Imaging Retina. 2018 May;49(5):313-9.

3 Kiss S, Dugel PU, Khanani AM, Broder MS, Chang E, Sun GH, et al. Endophthalmitis rates among patients receiving intravitreal anti-VEGF injections: a USA claims analysis. Clin Ophthalmol. 2018 Aug;12:1625-35.

4 Rayess N, Rahimy E, Storey P, Shah CP, Wolfe JD, Chen E, et al. Postinjection endophthalmitis rates and characteristics following intravitreal bevacizumab, ranibizumab, and aflibercept. Am J Ophthalmol. 2016 May;165:88-93.

5 Busch C, Iglicki M, Okada M, Gabrielle PH, Cohen S, Mariussi M, et al.; for the International Retina Group (IRG). Causative pathogens of endophthalmitis after intravitreal antiVEGF injection: an international multicenter study. Ophthalmologica. 2019;241(4):211-9.

6 Doshi RR, Leng T, Fung AE. Povidone-iodine before lidocaine gel anesthesia achieves surface antisepsis. Ophthalmic Surg Lasers Imaging. 2011 Jul-Aug;42(4):346-9.

7 Merani R, Hunyor AP. Endophthalmitis following intravitreal anti-vascular endothelial growth factor (VEGF) injection: a comprehensive review. Int J Retina Vitreous. 2015 Jul;1(1):9.

8 Speaker MG, Menikoff JA. Prophylaxis of endophthalmitis with topical povidone-iodine. Ophthalmology. 1991 Dec;98(12):1769-75.

9 Friedman DA, Mason JO 3rd, Emond T, McGwin G Jr. Povidone-iodine contact time and lid speculum use during intravitreal injection. Retina. 2013 May;33(5):975-81.

10 Helbig H, Noske W, Kleineidam M, Kellner U, Foerster MH. Bacterial endophthalmitis after anterior chamber paracentesis. Br J Ophthalmol. 1995 Sep;79(9):866. 


\section{Case Reports in Ophthalmology}

\begin{tabular}{l|l}
\hline DOI: $10.1159 / 000505227$ & $\begin{array}{l}\text { ( ) 2020 S. Karger AG, Basel } \\
\text { www.karger.com/cop }\end{array}$ \\
\hline
\end{tabular}

Rohowetz et al.: Endophthalmitis Caused by Agrobacterium radiobacter following Intravitreal Aflibercept for Diabetic Retinopathy

11 Avery RL, Bakri SJ, Blumenkranz MS, Brucker AJ, Cunningham ET Jr, D’Amico DJ, et al. Intravitreal injection technique and monitoring: updated guidelines of an expert panel. Retina. 2014 Dec;34 Suppl 12:S1-18

12 Lai CC, Teng LJ, Hsueh PR, Yuan A, Tsai KC, Tang JL, et al. Clinical and microbiological characteristics of Rhizobium radiobacter infections. Clin Infect Dis. 2004 Jan;38(1):149-53.

13 Chen CY, Hansen KS, Hansen LK. Rhizobium radiobacter as an opportunistic pathogen in central venous catheter-associated bloodstream infection: case report and review. J Hosp Infect. 2008 Mar;68(3):203-7.

14 Landron C, Le Moal G, Roblot F, Grignon B, Bonnin A, Becq-Giraudon B. Central venous catheter-related infection due to Agrobacterium radiobacter: a report of 2 cases. Scand J Infect Dis. 2002;34(9):693-4.

15 Paphitou NI, Rolston KV. Catheter-related bacteremia caused by Agrobacterium radiobacter in a cancer patient: case report and literature review. Infection. 2003 Dec;31(6):421-4.

16 Hanada S, Iwamoto M, Kobayashi N, Ando R, Sasaki S. Catheter-related bacteremia caused by Agrobacterium radiobacter in a hemodialysis patient. Intern Med. 2009;48(6):455-7.

17 Mastroianni A, Coronado 0, Nanetti A, Manfredi R, Chiodo F. Agrobacterium radiobacter pneumonia in a patient with HIV infection. Eur J Clin Microbiol Infect Dis. 1996 Dec;15(12):960-3.

18 Al-Abdullah AA, Al-Falah M, Al-Rashaed S, Khandekar R, Arevalo JF. Endophthalmitis caused by Rhizobium radiobacter after posterior chamber phakic intraocular lens implantation to correct myopia. J Refract Surg. 2015 Aug;31(8):561-3.

19 Miller JM, Novy C, Hiott M. Case of bacterial endophthalmitis caused by an Agrobacterium radiobacter-like organism. J Clin Microbiol. 1996 Dec;34(12):3212-3.

20 Moreau-Gaudry V, Chiquet C, Boisset S, Croize J, Benito Y, Cornut PL, et al.; French Institutional Endophthalmitis Study (FRIENDS) Group. Three cases of post-cataract surgery endophthalmitis due to Rhizobium (Agrobacterium) radiobacter. J Clin Microbiol. 2012 Apr;50(4):1487-90.

21 Namdari H, Hamzavi S, Peairs RR. Rhizobium (Agrobacterium) radiobacter identified as a cause of chronic endophthalmitis subsequent to cataract extraction. J Clin Microbiol. 2003 Aug;41(8):3998-4000.

22 Pierre-Filho PT, Ribeiro AP, Passos ED, Torigoe M, de Vasconcellos JP. Endophthalmitis caused by Agrobacterium radiobacter. Scand J Infect Dis. 2003;35(6-7):410-1.

23 Plotkin GR. Agrobacterium radiobacter prosthetic valve endocarditis. Ann Intern Med. 1980 Dec;93(6):83940.

24 Joshi L, Morarji J, Tomkins-Netzer O, Lightman S, Taylor SR. Rhizobium radiobacter endophthalmitis following intravitreal ranibizumab injection. Case Rep Ophthalmol. 2012 Sep;3(3):283-5.

25 Alnor D, Frimodt-Møller N, Espersen F, Frederiksen W. Infections with the unusual human pathogens Agrobacterium species and Ochrobactrum anthropi. Clin Infect Dis. 1994 Jun;18(6):914-20.

26 Schargus M, Werner BP, Geerling G, Winter G. Contamination of anti-VEGF drugs for intravitreal injection: how do repackaging and newly developed syringes affect the amount of silicone oil droplets and protein aggregates? Retina. 2018 Oct;38(10):2088-95.

27 Aras C, Ozdamar A, Karacorlu M, Ozkan S. Silicone oil in the surgical treatment of endophthalmitis associated with retinal detachment. Int Ophthalmol. 2001;24(3):147-50.

28 Ozdamar A, Aras C, Ozturk R, Akin E, Karacorlu M, Ercikan C. In vitro antimicrobial activity of silicone oil against endophthalmitis-causing agents. Retina. 1999;19(2):122-6.

29 Bosshard PP, Zbinden R, Abels S, Böddinghaus B, Altwegg M, Böttger EC. 16S rRNA gene sequencing versus the API 20 NE system and the VITEK 2 ID-GNB card for identification of nonfermenting Gram-negative bacteria in the clinical laboratory. J Clin Microbiol. 2006 Apr;44(4):1359-66.

30 Martinez JL, Martinez-Suarez J, Culebras E, Perez-Diaz JC, Baquero F. Antibiotic inactivating enzymes from a clinical isolate of Agrobacterium radiobacter. J Antimicrob Chemother. 1989 Feb;23(2):283-4.

31 Edmond MB, Riddler SA, Baxter CM, Wicklund BM, Pasculle AW. Agrobacterium radiobacter: a recently recognized opportunistic pathogen. Clin Infect Dis. 1993 Mar;16(3):388-91.

32 Kokame GT, Yannuzzi NA, Shantha JG, Yamane M, Relhan N, Gross J, et al. Involution of neovacular agerelated macular degeneration after endophthalmitis. Retin Cases Brief Rep. 2019 Mar;1. 


\section{Case Reports in Ophthalmology}

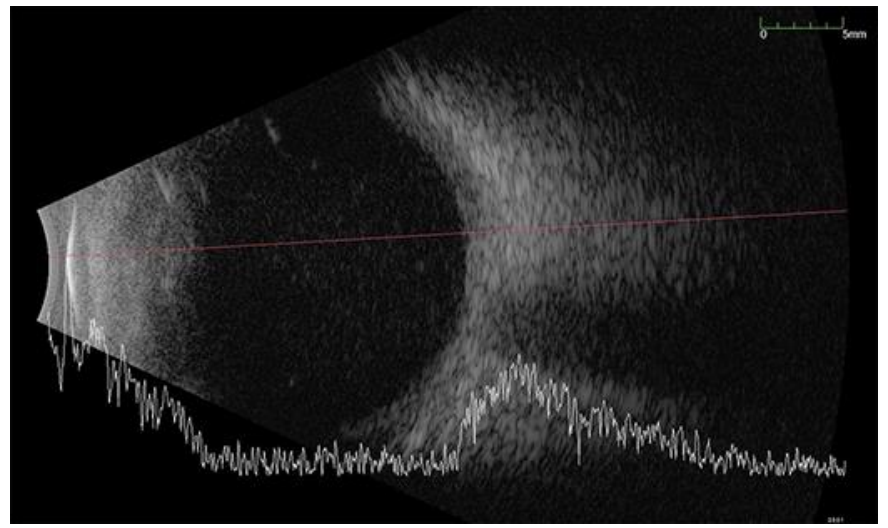

Fig. 1. B-scan demonstrating diffuse opacities and hyperechogenicity of the vitreous cavity.
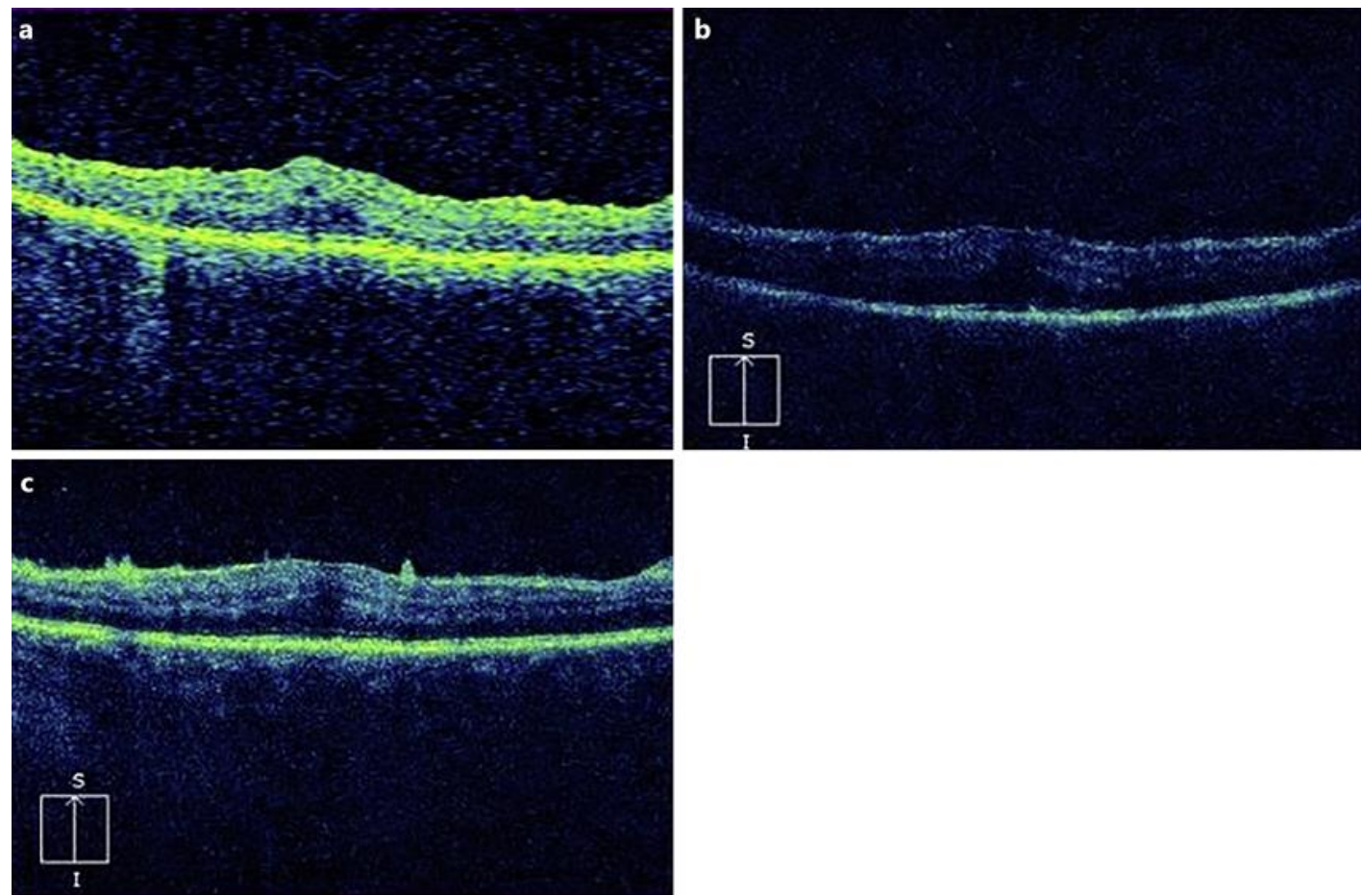

Fig. 2. a Optical coherence tomography (OCT) on the day of aflibercept injection, demonstrating trace intraretinal fluid. b OCT 5 days after diagnosis of endophthalmitis, revealing globally diminished signal transmission with mild intraretinal fluid. c OCT 7 days after diagnosis of endophthalmitis demonstrating decreased intraretinal fluid and several hyperreflective preretinal foci. 